\title{
SEXUAL STAGES IN TRYPANOSOMES AND IMPLICATIONS
}

\author{
L. JENNI
}

\begin{abstract}
SUMMARY
The basis for concluding that a system of genetic exchange exists in African trypanosomes of the Trypanosoma brucei group is outlined by the accumulated data from variation in natural parasite populations and from laboratory crossing experiments. The results
\end{abstract}

indicate that these parasites can complete their life cycle either with or without genetic exchange. This sexual event involves meiosis and syngamy, but the order of these processes and the sexual stages involved are not yet known.
RÉSUMÉ : Stades sexuels chez les trypanosomes et perspectives.

Les bases pour conclure à un système d'échange génétique chez les trypanosomes africains du groupe Trypanosoma brucei sont fournies par l'accumulation des données recueillies sur les variations observées en milieu naturel chez les populations de parasites et par les expériences de croisement génétique en laboratoire. Les résultats indiquent que ces parasites peuvent compléter leur cycle de vie avec ou sans échange génétique. Cette mutation sexuelle implique méiose et syngamie, mais l'ordre de ces processus et les stades sexuels impliqués ne sont pas encore connus.

\section{REPRODUCTION AND SEXUALITY}

IN AFRICAN TRYPANOSOMES

Trypanosomes of the subgenus Trypanozoon primarily replicate by binary fission and have a complex life cycle in the Glossina vector and in mammalian hosts. In both groups of hosts, they differentiate into several morphologically distinct forms. In the following, the name Trypanosoma brucei will be used in the broad sense, $i$. e. include all subgenus types (T. brucei, T. rhodesiense and T. gambiense).

Although much is known about the cyclical development of $T$. brucei, the important question of whether these organisms pass a sexual cycle has been debated since the original description of these parasites (Baker 1989, Tait 1983).

The existence of genetic exchange between $T$. brucei trypanosomes could account for the evolution of extensive molecular variation and polymorphism observed (Gibson et al. 1980). Direct observations of meiosis and mitosis are lacking as trypanosome chromosomes do not condense throughout the cell division cycle and thus cannot be visualized by classical cytological methods. However, indirect evidence of genetic exchange has been obtained from the analysis of enzyme electrophoretic variation between natural parasite populations from field isolations (Gibson et al. 1980, Tait 1980). Tait (1983) compared the observed and expected frequencies of iso-enzyme patterns of $T$. brucei

Swiss Tropical Institute, Socinstr. 57, 4002 Basel, Switzerland. populations and he found suggestive evidence for the existence of a gene exchange system.

Essential to the analysis of genetic exchange is the knowledge of the ploidy and DNA content of the organism under study. Three independent series of experiments have revealed that $T$. brucei organisms are diploid for most genes. This conclusion is based on the analysis of enzyme electrophoretic banding patterns (Gibson et al. 1980, Tait 1980), the kinetic complexity of the genome and the measured DNA content (Borst et al. 1982) as well as on the data by Gibson et al. (1985) on the analysis of restriction fragment length polymorphisms (RFLP's) of single copy genes.

\section{Genetic eXchange In Trypanosoma brucei}

Direct evidence for genetic exchange between two cloned populations of $T$. brucei has recently been obtained by Jenni et al. (1986). The cloned parental populations had been selected from a number of recent field isolates after extensive characterization by iso-enzyme electrophoresis, southern blot analysis of genes encoding for variable surface antigens, analysis of fitness for life cycle development and vector specificity. Three cloned progeny were recovered which exhibited "hybrid» characters for different genotypic and phenotypic parameters including 2D-PAGE patterns of parental clones and hybrid progeny (Pearson and Jenni 1989). However, the analysis of several cloned progeny showed that genetic exchange is not obligatory for the successful cyclical development in the fly. Hybrid 
progeny could be recovered from clones directly initiated with single metacyclic forms, which indicates that genetic exchange has occured during cyclical development of the trypanosomes in Glossina. The analysis of cyclically retransmitted hybrid progeny showed that the individual clones were stable with regard to their genotype and phenotype.

Tait and Turner (1990) have recently summarized and reviewed the number of crosses which have been carried out so far (Gibson 1989, Jenni et al. 1986, Paindavoine et al. 1986, Sternberg et al. 1988, Sternberg et al. 1989, Wells et al. 1987). Six successful experiments from different laboratories have been listed which produced 61 hybrid clones in total. In one experiment (Gibson 1989), a completely new parental pair of trypanosomes was used while in the other crosses at least one of the " original " parental clones (STIB 247 or STIB 386) was used. In addition, using T. brucei clone STIB 247 and another clone from East Africa (STIB 777) for simultaneous transmission, 4 new hybrid clones could be isolated from one tsetse fly (Schweizer et al., unpublished) which fall into two different groups after current preliminary iso-enzyme analyses.

So far, parental clones of $T$. gambiense were not involved in any of the successful cross experiments.

\section{FREQUENCY OF GENETIC EXCHANGE}

The genetic exchange observed under laboratory conditions may not be a regular feature of the life cycle of $T$. brucei in a natural field environment. Although the predicted genotype frequencies were generally in a good agreement with those data obtained from natural populations, significant deviations from Hardy-Weinberg equilibrium were observed in one population of T. brucei (Tait 1983). Cibulkis (1988) carried out an in depth statistical analysis and he concluded that if sample size is small, agreement cannot definitely be interpreted as indicating that genetic exchange is occuring.

The frequency and timing of genetic exchange between the two « original » parental clones STIB 247 and STIB 386 has been investigated (Schweizer et al. 1988). Series of subsequent bloodstream populations initiated in mice by the bite of 23 infective flies were characterized by iso-enzyme electrophoresis. Both parental clones were homozygous for iso-citrate dehydrogenase (ICD) and alkaline phosphatase (AP). Heterozygous patterns for both enzymes have been found in progeny from at least 9 of the 23 tsetse flies. This indicates that the frequency of genetic exchange can be high if compatible clones develop together in the same vector at optional conditions. There was further evidence that hybrid trypanosomes were not extruded continuously but could alter over time with the detection of either or both of the parental clones. This also indicates that mating is not obligatory for cyclical development in the tsetse fly, but sexual events seem to be co-existent with asexual development in the same individual vector.

\section{Sexual stages}

Although there still exists some controversy about the mechanisms of gene exchange in $T$. brucei with regard to a classical mendelian mechanism, the basic genetic rules of the sexual process in $T$. brucei have now been established and summarized by Tait and Turner (1990). The compiled data clearly indicate that meiosis and syngamy do occur in the tsetse fly but the order of these genetic events is still not known. There is no clear cytological observation of the corresponding sexual cell types and observed variations in DNA content of some progeny are difficult to interpret. Baker (1989) has reviewed the available data on observations of several workers on particular forms which were interpreted as being involved in sexual fusions. This important lack of information clearly needs a detailed analysis and further work.

Preliminary results from experiments with the objective to localize the sexual stages of $T$. brucei in Glossina indicate that hybrid trypanosomes may not be formed within the midgut parts of the vector (Schweizer et al. unpublished). If mating represents a rare event which may not occur continuously in the same vector, the detection of the origin of gene exchange and the corresponding sexual stages may be difficult but is however indispensable for the determination of the precise mechanisms of meiosis and syngamy.

\section{Conclusions}

Genetic exchange and recombination in $T$. brucei are of fundamental importance in the generation of diversity. Organisms which possess a mating system are capable of producing a greater range of novel genotypes than those which develop by asexual reproduction only. The ability for genetic exchange could allow this group of trypanosomes to generate progeny with novel specifications such as new sets of variable surface antigens, drug resistance and resistance against normal host factors. The latter would allow the establishment in new hosts. Genetic exchange could have some implications for the successful development of new methods of disease control in the future.

Acknowledgment. - We would like to thank the Swiss National Science Foundation for supporting the above described work of our laboratory (grants No. 3.252-085 and 31-25367.88).

\section{REFERENCES}

Baker J. R. : Sexual processes in parasitic protozoa. Int. J. Parasitol., 1989, 19, 465-472.

Borst P., Van der Ploeg M., Van Hoek J. F. M., Tas J., James J. : On the DNA content and ploidy of trypanosomes. Mol. Biochem. Parasitol., 1982, 6, 13-23. 
Cibulkis R. E. : Origins and organization of genetic diversity in natural populations of Trypanosoma brucei. Parasitology, 1988, 96, 303-322.

Gibson W. C. : Analysis of a genetic cross between Trypanosoma brucei rhodensiense and T. b. brucei. Parasitology, 1989, 99, 391-401.

Gibson W. C., Marshall T. F. de C., Godfrey D. G. : Numerical analysis of enzyme polymorphism: a new approach to the epidemmiology and taxonomy of trypanosomes of the subgenus Trypanozoon. Adv. Parasitol., 1980, 18, 175-246.

Gibson W. C., Osinga K. A., Michels P. A. M., Borst P. : Trypanosomes of subgenus Trypanozoon are diploid for housekeeping genes. Mol. Biochem. Parasitol., 1985, 16, 231-242.

Jenni L., Marti S., Schweizer J., Betschart B., Le Page R. W. F., Wells J. M., Tait A., Paindavoine P., Pays E., Steinert M. : Hybrid formation between African trypanosomes during cyclical transmission. Nature, 1986, 322, 173-175.

Paindavoine P., Zampetti-Bosseler F., Pays E., Schweizer J., Guyaux M., Jenni L., Steinert M. : Trypanosome hybrids generated in tsetse flies by nuclear fusion. EMBO J., 1986, 5, 3631-3636.

Pearson T. W., Jenni L. : Detection of hybrid phenotypes in
African trypanosomes by high resolution two-dimensional gel electrophoresis. Parasitol. Res., 1989, 76, 63-67.

Schweizer J., Tait A., Jenni L. : The timing and frequency of hybrid formation in African trypanosomes during cyclical transmission. Parasitol. Res., 1988, 75, 98-101.

Sternberg J., Tait A., Haley S., Wells J. M., Le Page R. W. F., Schweizer J., Jenni L. : Gene exchange in African trypanosomes: characterisation of a new hybrid genotype. Mol. Biochem. Parasitol., 1988, 27, 191-200.

Sternberg J., Turner C. M. R., Wells J. M., RanfordCartwright L. S., Le Page R. W. F., Tait A. : Gene Exchange in African trypanosomes: frequency and allelic segregation. Mol. Biochem. Parasitol., 1989, 34, 269-280.

Tait A. : Evidence for diploidy and mating in trypanosomes. Nature, 1980, 287, 536-538.

Tait A. : Sexual processes in the kinetoplastida. Parasitology, 1983, $86,29-57$.

Tait A., Turner C. M. R. : Genetic exchange in Trypanosoma brucei. Parasitology Today, 1990, 6, 70-75.

Wells J. M., Prospero T. D., Jenni L., Le Page R. W. F. : DNA contents and molecular karyotypes of hybrid Trypanosoma brucei. Mol. Biochem. Parasitol., 1987, 24, 103-116. 